\title{
Prevalence of the Use of Oral Contraceptives and Hormone Replacement Therapy in Japan: The Japan Nurses' Health Study
}

\author{
Toshiyuki Yasui ${ }^{1}$, Yuki Ideno ${ }^{2}$, Hiromitsu Shinozaki ${ }^{3}$, Yoshikazu Kitahara ${ }^{4}$, Kazue Nagai $^{3}$, \\ and Kunihiko Hayashi ${ }^{3}$, for the JNHS Research Group
}

\author{
${ }^{1}$ Department of Reproductive and Menopausal Medicine, Institute of Biomedical Sciences, Tokushima University Graduate School, Tokushima, Japan \\ ${ }^{2}$ Center for Mathematics and Data Science, Gunma University, Maebashi, Japan \\ ${ }^{3}$ Graduate School of Health Sciences, Gunma University, Maebashi, Japan \\ ${ }^{4}$ Department of Obstetrics and Gynecology, Gunma University Graduate School of Medicine, Maebashi, Japan
}

Received May 18, 2020; accepted October 16, 2020; released online October 31, 2020

\begin{abstract}
Background: There have been few community-based epidemiological studies in which the prevalence of exogenous hormone use, including the use of oral contraceptives (OCs) and hormone replacement therapy (HRT), has been accurately assessed in Japan.

Methods: We have been conducting repeated surveys of participants in the Japan Nurses' Health Study (JNHS), as a nationwide prospective cohort study, since 2001. We determined the prevalence of exogenous hormone use at baseline and during a 10-year follow-up period. A total of 15,019 female nurses participated in the JNHS follow-up cohort. We determined the prevalence of OC use in 14,839 women $<60$ years of age at baseline and the prevalence of HRT use in 7,915 women, excluding premenopausal women, at the last time they answered a questionnaire. The duration of HRT use was estimated using the Kaplan-Meier method.

Results: Six percent of the participants used OCs. The proportion of HRT users who stopped HRT before the baseline survey, the proportion of women using HRT during the follow-up period, and the proportion of all of the participants who had used HRT were $3.2 \%, 10.6 \%$, and $13.8 \%$, respectively. The median duration of HRT use was 2 years.

Conclusions: The lifetime prevalences of exogenous hormone use during this prospective study conducted in Japanese nurses were $6.0 \%$ for OCs and $13.8 \%$ for HRT. The information obtained in this study will be useful for clarification of the association between exogenous estrogen exposure and estrogen-related diseases as future research.
\end{abstract}

Key words: hormone replacement therapy; oral contraceptive; prevalence; nurse

Copyright (๑) 2020 Toshiyuki Yasui et al. This is an open access article distributed under the terms of Creative Commons Attribution License, which permits unrestricted use, distribution, and reproduction in any medium, provided the original author and source are credited.

\section{INTRODUCTION}

In women of reproductive age, oral contraceptives (OCs) are the most effective and widely used forms of contraception. Indeed, in the United States, more than $80 \%$ of sexually active women aged 15-44 years have reported using OCs. ${ }^{1}$ A survey conducted by the Japan Family Planning Association showed that the prevalence of OC use in Japan in 2004 was 3.0\%. ${ }^{2}$ However, there have been few epidemiological studies in which the extent of OC use was assessed in a longitudinal study in Japan.

Hormone replacement therapy (HRT) has an important role in the management of menopausal symptoms and osteoporosis. According to the Women's Health Initiative (WHI) reports in 2002 and 2004, no preventive effects of HRT on cardiovascular diseases were found..$^{3,4}$ In the United States, it was reported that the annual proportion of women aged 50-74 years who were on HRT declined from $42 \%$ in 2001 to $28 \%$ in $2003 .{ }^{5}$ The proportion of women undergoing HRT also decreased in 17 European countries. ${ }^{6}$ However, the timing hypothesis for benefits and risks of HRT showed that women younger than 60 years of age or within 10 years after menopause with menopausal symptoms have many benefits of HRT and few risks from HRT. ${ }^{7}$ Thereafter, the effects of the route of administration and the dosages and types of estrogen and progestogen were investigated, and it was suggested that a personalized approach should be used for therapy. ${ }^{8}$

There have been many studies on the prevalence of HRT in which the prevalence was assessed at a single time point. The estimated proportions of current users of HRT in women aged 45-69 years were 13.2\% in Finland, 5.3\% in Sweden, and 9.7\% in Belgium in $2013 .{ }^{9}$ It was also reported that $11.8 \%$ of menopausal women in Australia were current users of HRT at the time of a survey conducted in $2010 .^{10}$ In Japan, a cross-sectional survey conducted in Takayama City in 1992 showed that only $9.3 \%$ of women aged 45-64 years had ever used HRT and that only $2.5 \%$ of women were current users of HRT at the time of the survey. ${ }^{11}$ However, there have been few community-based epidemiological 
studies in which HRT use was assessed in a longitudinal study, except for some prospective cohort studies (eg, the Study of Women's Health Across the Nation, the Nurses' Health Study and the Danish Nurses Cohort Study). ${ }^{12-15}$

The prevalences of exogenous hormone use, including the use of OCs and HRT, in previous studies differed depending on the study design. The prevalence at a single time point in a crosssectional study may differ from that during a longitudinal study because steady state prevalence depends not only on the incidence of commencing drug use but also on the mean duration of use. ${ }^{16}$ The prevalence of drug use determined in a longitudinal study is likely to be closer to the true lifetime prevalence.

Simultaneous assessments of the prevalence of OC use and the prevalence of HRT use would provide important epidemiological and clinical information for women during their lifetime. Determination of the total amount of OC use and total amount of HRT use in various life stages is necessary to examine the effects of cumulative exposure to exogenous estrogen in a women's lifetime, although ages, reasons for use and durations of use are different for OCs and HRT.

We assessed the prevalence of exogenous reproductive hormone use, including OC use and HRT use, as the lifetime prevalence in Japan before the baseline survey and during a 10year follow-up period that was based on biennial surveys of the Japan Nurses' Health study (JNHS) population, as a large prospective cohort study. We also estimated the cumulative incidence of HRT use using the Kaplan-Meier method. The age at which HRT use commenced, the duration of HRT use, and the HRT administration route were also investigated.

\section{METHODS}

\section{Data collection and study participants}

The JNHS was a large prospective cohort study designed to investigate the effects of lifestyle and healthcare practices on the health of Japanese women. The details of the study design have been previously described. ${ }^{17} \mathrm{~A}$ cross-sectional baseline survey was conducted between 2001 and 2007. The target population was working women who were 21 years of age or older and lived in Japan at the time of the baseline survey, and the source population was nurses, public health nurses and midwives. Each applicant was mailed a self-administered questionnaire regarding their basic demographic characteristics; lifestyle habits; physical condition; reproductive history, including questions related to menstrual status, such as menstruation cycle, existence of menopause, day of last menstruation, and cause of menopause; and use of hormonal agents, together with a list of female hormonal drugs with pictures.

A total of 49,927 female nurses participated in the JNHS crosssectional survey. Of the 49,927 women, 15,019 women agreed to participation in the follow-up survey. In the baseline survey and biennially during the follow-up study, we asked for information on menopausal status, age at menopause, cause of menopause (natural menopause, surgical menopause, menopause secondary to radiation therapy or chemotherapy, or any other cause), and any past history of unilateral/bilateral oophorectomy or hysterectomy. Since age at menopause was estimated using the Kaplan-Meier method to be 54 years in $90 \%$ of the women who had undergone natural menopause in the JNHS population, ${ }^{18}$ the age at menopause was set to 54 years for women who underwent hysterectomy.

\section{Identification of OC and HRT users}

Previous use of female hormone preparations was ascertained before and after menopause (never used, had used before the baseline survey, or currently using). In the baseline survey, the participants identified the specific hormone preparation using the list and pictures of drugs. With regard to OCs, we asked about the use of exogenous female hormones other than those used in HRT before the baseline survey and during the 10-year study period. Three gynecologists used the specific drug name regardless of the purpose and identified $\mathrm{OC}$ users, considering that there are various purposes for using exogenous female hormones other than HRT, such as treatment for infertility, functional uterine bleeding, and dysmenorrhea, as well as contraception. With regard to HRT, the duration of HRT use, the type of HRT, and the pattern of progestogen use were ascertained. The three gynecologists identified HRT users via items such as the age they took hormones, the purposes of the hormone use, and their symptoms, as well as the type of drug and the specific drug name.

The Ethics Committee of Gunma University reviewed and approved the study (\#101, 2001 and \#18-11, 2007). Written informed consent was obtained from all participants.

\section{Statistical analysis}

A total of 15,019 female nurses participated in the JNHS cohort. With respect to OC use, data for 14,839 women who were less than 60 years of age in the baseline survey, an age range in which OCs might be used, were analyzed. We determined the sum of OC use including any past use as the lifetime prevalence of OC use. Data for 7,915 women, excluding premenopausal women with regular menstruation at the last time point of the longitudinal study who did not need treatment for menopausal symptoms, were analyzed to determine the prevalence of HRT use. HRT users were divided into the following seven groups for analysis: 1) women who had used HRT and had stopped HRT before the baseline survey, 2) women who had used HRT before the baseline survey and stopped HRT during the longitudinal study period, 3) women who had used HRT before the baseline survey and were using HRT at the last time they answered a questionnaire during the 10-year follow-up survey, 4) women who had used HRT before the baseline survey and were using HRT at the time of the 10-year survey, 5) women who started HRT after the baseline survey and stopped HRT before the 10year survey, 6) women who started HRT after the baseline survey and were using HRT at the last time they answered a questionnaire and did not respond to the 10-year survey, and 7) women who started HRT after the baseline survey and were using HRT at the time of the 10-year survey (Figure 1). The HRT users included women who had stopped using exogenous hormone preparations before the baseline survey and had never used HRT again during the survey period (past users) and women who had used exogenous hormone preparations at least once since the baseline survey (current users). According to the classification of HRT users, we calculated the simple prevalence of HRT use to estimate lifetime prevalence. Furthermore, the cumulative incidence of HRT use at the age of 60 years was estimated using the Kaplan-Meier method.

In women who had used hormonal preparations but with interruptions in their use, the duration of HRT was defined as the sum of the durations of HRT use. We estimated the median duration of HRT use via the Kaplan-Meier method to consider censored data. We also categorized the hormonal preparations 
Baseline (BL)

Past users

1 Use and cessation before BL

After the 10-year follow-up study (F10)

2 Use before BL and cessation during the study period

3 Use before BL and at the time of the final survey, but no response to the F10 survey

4 Use before BL and at F10

5 Use after BL and cessation before F10

6 Use after BL and at the time of the final survey, but no response to the F10 survey

7 Use after BL and at F10

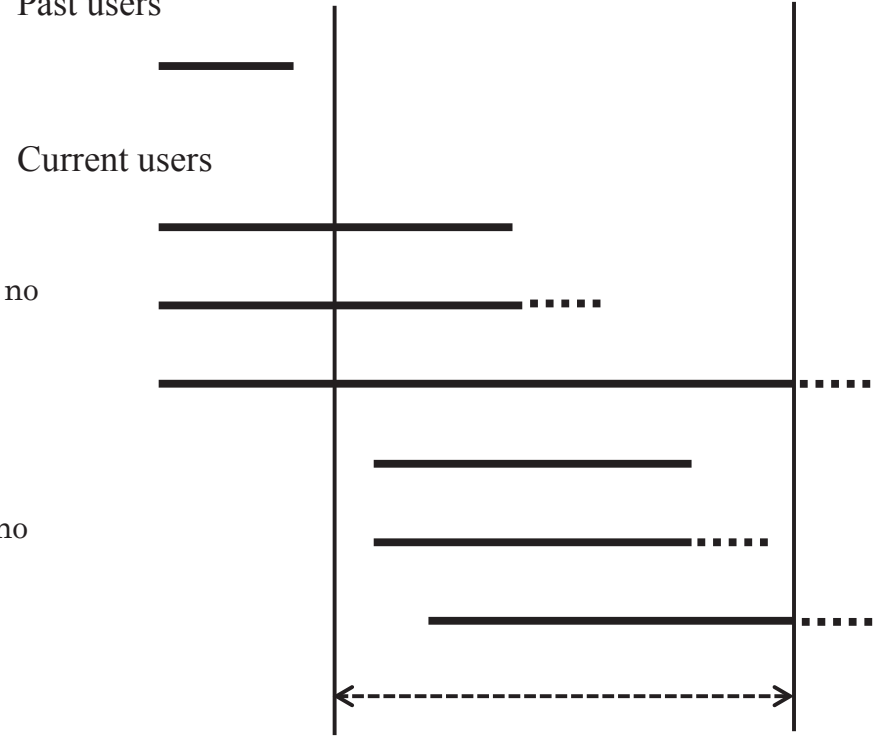

Study period (10 years)

Figure 1. Classification of HRT users. BL, baseline; F10, after the 10-year follow-up study; HRT, hormone replacement therapy; OC, oral contraceptive.

according to their route of administration (oral, transdermal or transvaginal), and multiple answers were permitted. Statistical analyses were performed using SAS ver 9.4 (SAS Institute Inc., Cary, NC, USA).

\section{RESULTS}

The characteristics of the 14,839 women for whom OC use was analyzed are shown in Table 1 . The prevalence of OC use in this population was $6.0 \%$. The prevalences of OC use were $2.8 \%$ in women who were born in the 1950s, $7.8 \%$ in women who were born in the 1960s, $10.6 \%$ in women who were born in the 1970s, and $20.8 \%$ in women who were born after the 1980 s.

The characteristics of the 7,915 women for whom HRT use was analyzed are shown in Table 2 . The proportion of the cohort that had never used HRT was $86.2 \%$. As shown in Table 3, the prevalence of HRT use before the baseline survey (past users) was $3.2 \%(n=255)$ and the prevalence of HRT use during the study period (current users) was $10.6 \%(n=840)$, making a total prevalence of HRT use of $13.8 \%(n=1,095)$. The cumulative incidence of HRT use at the age of 60 years was estimated to be $15.7 \%$ by the Kaplan-Meier method (Figure 2).

The proportions of the women who received HRT were $12.3 \%$ in women without hysterectomy and oophorectomy, $13.6 \%$ in women with hysterectomy, $15.5 \%$ in women with unilateral oophorectomy, $35.9 \%$ in women with bilateral oophorectomy, $20.0 \%$ in women with unilateral oophorectomy and hysterectomy, and $46.0 \%$ in women with bilateral oophorectomy and hysterectomy.

Of the women who had used HRT at any time $(n=1,095)$, $66.2 \%$ of the women started HRT between the ages of 45 and 54 years (Table 4). The proportion of women who started HRT at the age of $>60$ years was $2.1 \%$. The proportions of women who used HRT for $1-3$ years, $>6$ years, and $>10$ years were $32.7 \%$,
$20.2 \%$, and $9.2 \%$, respectively (Table 4 ). The median duration of HRT use was estimated to be 2 years by the Kaplan-Meier method (interquartile range: $1-5$ years; $n=1,092$ with exclusion of three women whose duration of HRT use was unclear) (Figure 3). With regard to the route of estrogen administration, $65.5 \%$ took it orally $(717 / 1,095), 28.8 \%$ took it transdermally $(315 / 1,095)$, and $1.2 \%$ took it vaginally $(13 / 1,095)$. The proportion of women for whom the route of administration was unclear was $12.8 \%(140 / 1,095)$. We counted separately the women who changed the route of administration from oral to transdermal administration.

\section{DISCUSSION}

We have shown that the lifetime prevalence of OC use for any reason is $6 \%$ in female Japanese nurses. Cross-sectional population surveys conducted in 1989-1997 showed that the prevalence of OC use in women aged 34-44 years was $>20 \%$ in Australia, Belgium, France, and East Germany, ${ }^{19}$ and it was reported that $82 \%$ of sexually experienced women used OCs during the period from 2006 to 2008 in the United States. ${ }^{1}$ In the United Kingdom, the prevalence of hormonal contraceptive use among female adolescents increased from $13.7 \%$ in 2002 to $19.0 \%$ in $2011 .^{20}$ The lifetime prevalence of OC use by Japanese nurses was extremely low compared with those previously reported prevalences. OCs were approved by the Japanese government in 1999. Japan was the last country in the world to approve OCs. The delay in approval of OCs because of the fear about the potential spread of sexually transmitted diseases if $\mathrm{OC}$ use replaces condom use might explain the lower popularity of OCs in Japan. ${ }^{21}$ The current use of OC may have changed since about 20 years have passed since OCs were approved in Japan. ${ }^{22}$ We analyzed the prevalences of OC used according to generations, and our results showed that younger women were 
Table 1. Characteristics of the study population assessed for OC user $(n=14,839)$

\begin{tabular}{|c|c|c|c|}
\hline & & Number & Proportion (\%) \\
\hline \multirow[t]{4}{*}{ Age at baseline survey, years } & $20-29$ & 498 & 3.4 \\
\hline & $30-39$ & 5,920 & 39.8 \\
\hline & $40-49$ & 5,698 & 38.4 \\
\hline & $50-59$ & 2,723 & 18.4 \\
\hline \multirow[t]{3}{*}{ Menstrual status at baseline survey } & premenopause & 12,227 & 82.4 \\
\hline & postmenopause & 2,116 & 14.3 \\
\hline & unclear & 496 & 3.3 \\
\hline \multirow[t]{3}{*}{ Menstrual status at the final survey } & premenopause & 7,104 & 47.9 \\
\hline & postmenopause & 7,139 & 48.1 \\
\hline & unclear & 596 & 4.0 \\
\hline \multirow[t]{5}{*}{ Body mass index at baseline survey, $\mathrm{kg} / \mathrm{m}^{2}$} & $<18.5$ & 1,279 & 8.6 \\
\hline & $\geq 18.5$ and $<25.0$ & 11,443 & 77.1 \\
\hline & $\geq 25.0$ and $<30.0$ & 1,622 & 10.9 \\
\hline & $\geq 30.0$ & 276 & 1.9 \\
\hline & missing & 219 & 1.5 \\
\hline \multirow[t]{3}{*}{ Smoking at baseline survey } & no & 10,520 & 70.9 \\
\hline & yes & 4,206 & 28.3 \\
\hline & missing & 113 & 0.8 \\
\hline \multirow[t]{3}{*}{ Alcohol drinking habit at baseline survey } & no & 10,699 & 72.1 \\
\hline & yes & 3,470 & 23.4 \\
\hline & missing & 670 & 4.5 \\
\hline \multirow[t]{7}{*}{ Gravidity at baseline survey } & 0 & 3,565 & 24.0 \\
\hline & 1 & 1,574 & 10.6 \\
\hline & 2 & 3,648 & 24.6 \\
\hline & 3 & 3,135 & 21.1 \\
\hline & 4 & 1,547 & 10.4 \\
\hline & $\geq 5$ & 871 & 5.9 \\
\hline & missing & 499 & 3.4 \\
\hline \multirow[t]{6}{*}{ Parity at baseline survey } & 0 & 4,140 & 27.9 \\
\hline & 1 & 1,857 & 12.5 \\
\hline & 2 & 5,183 & 35.0 \\
\hline & 3 & 2,891 & 19.5 \\
\hline & $\geq 4$ & 362 & 2.4 \\
\hline & missing & 406 & 2.7 \\
\hline \multirow[t]{2}{*}{ Hysterectomy at the final survey } & yes & 1,031 & 7.0 \\
\hline & no & 13,808 & 93.0 \\
\hline \multirow[t]{3}{*}{ Oophorectomy at the final survey } & unilateral & 544 & 3.7 \\
\hline & bilateral & 279 & 1.9 \\
\hline & no & 14,016 & 94.4 \\
\hline
\end{tabular}

more likely to use OCs. Most of the participants in the present study were older than women who would most likely use OCs. Therefore, further study of younger women is needed to clarify the use of OCs in Japan in more detail.

In the present study, the lifetime prevalence of HRT use for women who had used HRT and stopped using HRT before the baseline survey was $3.2 \%$, the prevalence of HRT use during the 10 -year follow-up period was $10.6 \%$, and the total prevalence of HRT use for peri- and postmenopausal women in the study period was $13.8 \%$. The cumulative incidence of HRT use estimated using the Kaplan-Meier method was $15.7 \%$, which is considered to be closer to the true lifetime prevalence. Considering that the total prevalence could be regarded as being approximately $90 \%$ of the cumulative incidence (15.7\%) at the age of 60 years estimated by the Kaplan-Meier method, $13.8 \%$ is an appropriate value.

There have been few longitudinal studies on the prevalence of HRT use. In the Nurses' Health Study, it was shown that $15.8 \%$ of the participants used HRT during a 14-year period (1980-1994), ${ }^{13}$ and in the Danish Nurse Cohort Study, the prevalence of HRT use between 1993 and 1999 was 37.2\%. ${ }^{14}$ It has also been reported that $28.4 \%$ of the participants in a cohort study in Denmark used HRT during the period from 1995 to
$2010 .{ }^{15}$ The proportion of HRT users in the present study was lower than the proportions in those previous studies. European women start using HRT not only for symptomatic relief but also to reduce the risk of postmenopausal osteoporosis. ${ }^{23}$ In contrast, insurance coverage for the use of estrogen preparations for treatment of osteoporosis is limited in Japan, although the use of estrogen preparations for menopausal symptoms and estrogendeficiency symptoms is covered by insurance. ${ }^{24}$

The duration of HRT use is an important determinant of its prevalence. The prevalence of HRT use determined in a crosssectional study may be similar to that in a long-term longitudinal study if the duration of HRT use is long. However, the prevalence of HRT use determined in a cross-sectional survey may be lower if the duration of HRT use is short. We consider that the survey period in the present study in middle-aged and older women was sufficiently long for the prevalence determined in the present study to be close to the true lifetime prevalence.

$\mathrm{Du}$ et $\mathrm{al}^{25}$ reported that the proportion of long-term HRT users (>3 years) significantly increased from $60.2 \%$ in $1997-1999$ to $80.1 \%$ in $2003-2004$. Recently, Løkkegaard et al ${ }^{15}$ reported that the proportion of women who use HRT for 5-9 years is high and that $2-4$ years is the next most common duration of HRT use. The 
Table 2. Characteristics of the study population assessed for HRT user $(n=7,915)$

\begin{tabular}{|c|c|c|c|}
\hline & & Number & Proportion (\%) \\
\hline \multirow[t]{5}{*}{ Age at baseline survey, years } & $20-29$ & 5 & 0.1 \\
\hline & $30-39$ & 649 & 8.2 \\
\hline & $40-49$ & 4,375 & 55.2 \\
\hline & $50-59$ & 2,706 & 34.2 \\
\hline & $\geq 60 \mathrm{~s}$ & 180 & 2.3 \\
\hline \multirow[t]{3}{*}{ Menstrual status at baseline survey } & premenopause & 5,137 & 64.9 \\
\hline & postmenopause & 2,292 & 29.0 \\
\hline & unclear & 486 & 6.1 \\
\hline \multirow[t]{2}{*}{ Menstrual status at the final survey } & postmenopause & 7,319 & 92.5 \\
\hline & unclear & 596 & 7.5 \\
\hline \multirow[t]{5}{*}{ Body mass index at baseline survey, $\mathrm{kg} / \mathrm{m}^{2}$} & $<18.5$ & 428 & 5.4 \\
\hline & $\geq 18.5$ and $<25.0$ & 6,154 & 77.7 \\
\hline & $\geq 25.0$ and $<30.0$ & 1,082 & 13.7 \\
\hline & $\geq 30.0$ & 147 & 1.9 \\
\hline & missing & 104 & 1.3 \\
\hline \multirow[t]{3}{*}{ Smoking at baseline survey } & no & 5,653 & 71.4 \\
\hline & yes & 2,179 & 27.5 \\
\hline & missing & 83 & 1.1 \\
\hline \multirow[t]{3}{*}{ Alcohol drinking habit at baseline survey } & no & 5,513 & 69.7 \\
\hline & yes & 2,005 & 25.3 \\
\hline & missing & 397 & 5.0 \\
\hline \multirow[t]{7}{*}{ Gravidity at baseline survey } & 0 & 1,064 & 13.4 \\
\hline & 1 & 606 & 7.7 \\
\hline & 2 & 2,162 & 27.4 \\
\hline & 3 & 2,075 & 26.2 \\
\hline & 4 & 1,099 & 13.9 \\
\hline & $\geq 5$ & 645 & 8.1 \\
\hline & missing & 264 & 3.3 \\
\hline \multirow[t]{6}{*}{ Parity at baseline survey } & 0 & 1,255 & 15.9 \\
\hline & 1 & 861 & 10.9 \\
\hline & 2 & 3,320 & 41.9 \\
\hline & 3 & 2,013 & 25.4 \\
\hline & $\geq 4$ & 271 & 3.4 \\
\hline & missing & 195 & 2.5 \\
\hline \multirow[t]{2}{*}{ Hysterectomy at the final survey } & yes & 1,061 & 13.4 \\
\hline & no & 6,854 & 86.6 \\
\hline \multirow[t]{3}{*}{ Oophorectomy at the final survey } & unilateral & 435 & 5.5 \\
\hline & bilateral & 287 & 3.6 \\
\hline & no & 7,193 & 90.9 \\
\hline
\end{tabular}

Table 3. HRT users in each category

\begin{tabular}{lcc}
\hline & Number & Proportion (\%) \\
\hline Non-users & 6,820 & 86.2 \\
Users & 255 & 3.2 \\
1 Use and cessation before BL & 262 & 3.3 \\
2 Use before BL and cessation during the study period & 16 & 0.2 \\
3 Use before BL and at the time of the final survey, but no response to the F10 invitation & 364 & 0.5 \\
4 Use before BL and at F10 & 18 & 4.6 \\
5 Use after BL and cessation during the study period & 144 & 0.2 \\
6 Use after BL and at the time of the final survey, but no response to the F10 invitation & 1.8 \\
7 Use after BL and at F10 & \\
\hline
\end{tabular}

BL, baseline; F10, after the 10-year follow-up study.

International Menopause Society recommended in 2016 that the duration of HRT use should not be limited. ${ }^{26}$ Therefore, the proportion of long-term users may be increasing. In a study conducted in Japan in 1992, it was shown that 9.9\% of the women in the survey had used HRT for more than 5 years. ${ }^{11}$ In contrast, in the present study, $20.2 \%$ of the women used HRT for more than 6 years. This difference may be explained by differences in the study design since the results obtained in the study conducted in 1992 based on a cross-sectional survey, not a long follow-up survey. In the past 20 years in Japan, there has been not only an increase in the number of women in menopausal transition but also recognition of the effectiveness of HRT and increased awareness by both women and gynecological doctors of menopausal medicine due to the increase in availability of menopausal medicine.

It has been reported that benefits of HRT are likely to outweigh the risks if symptomatic women start HRT before the age of 60 


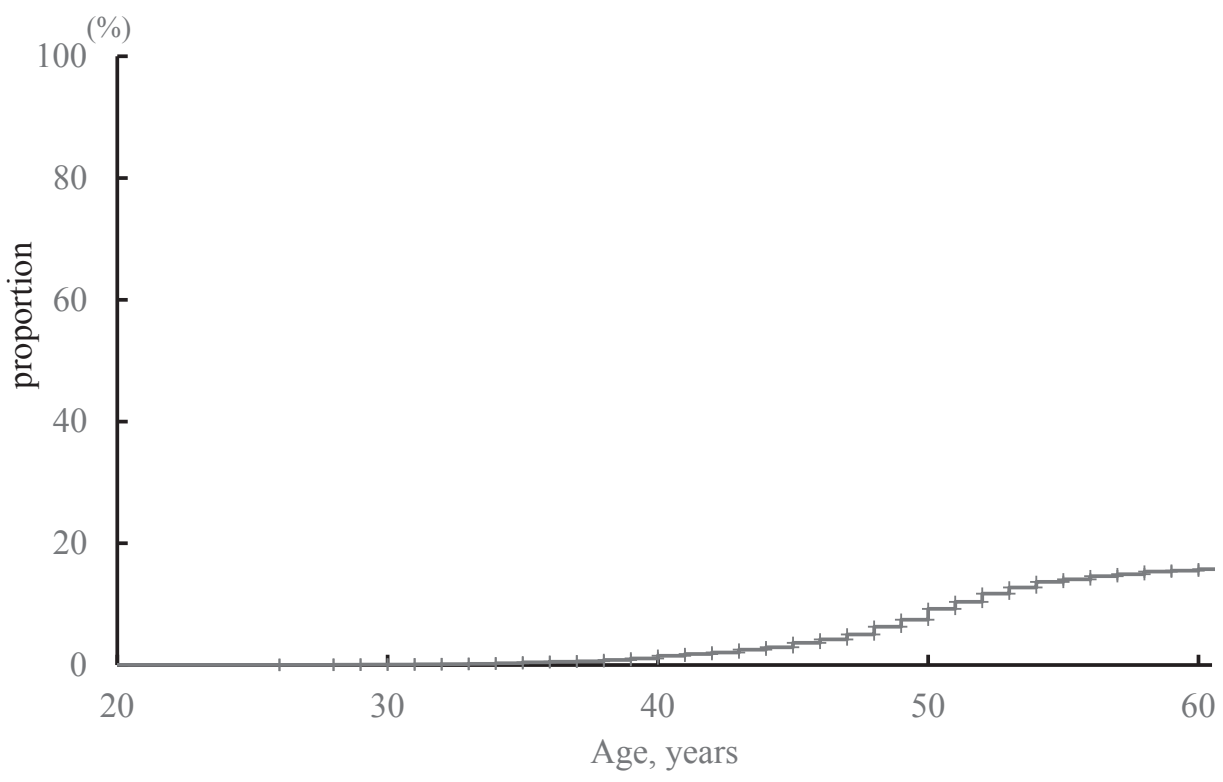

Figure 2. Cumulative incidence of HRT at the age of 60 years estimated using the Kaplan-Meier method

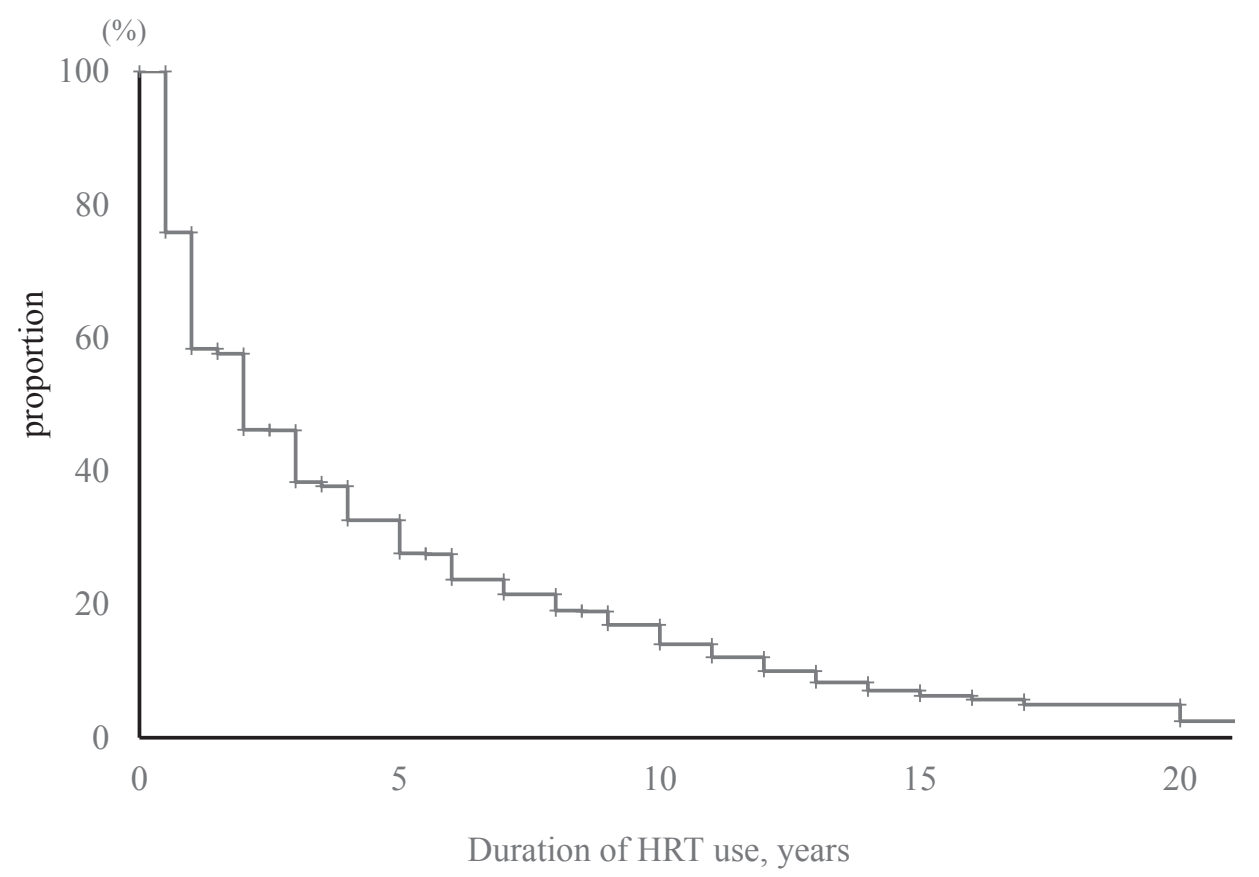

Figure 3. Duration of HRT use estimated using the Kaplan-Meier method

Table 4. Age when commencing HRT and the duration $(n=1,095)$

\begin{tabular}{llcc}
\hline & & Number & Proportion (\%) \\
\hline Age at the start of HRT, years & $<40$ & 84 & 7.7 \\
& $40-44$ & 143 & 13.1 \\
& $45-49$ & 336 & 30.7 \\
& $50-54$ & 389 & 35.5 \\
& $55-59$ & 77 & 7.0 \\
& $\geq 60$ & 23 & 2.1 \\
& missing & 43 & 3.9 \\
Duration, years & $<1$ & 286 & 26.1 \\
& $\geq 1$ and $<3$ & 358 & 32.7 \\
& $\geq 3$ and $<6$ & 227 & 20.7 \\
& $\geq 6$ and $<10$ & 120 & 11.0 \\
& $\geq 10$ & 101 & 9.2 \\
& unclear & 3 & 0.3 \\
\hline
\end{tabular}

years or within 10 years after menopause. ${ }^{7}$ The results of the present study showed that $66.2 \%$ of the women aged $45-54$ years had started HRT, and that percentage is close to the percentages reported in the United States and European countries. ${ }^{27,28}$ It was reported that the proportion of women who started HRT at more than 54 years of age in the period from 1990 to 2001 was $16.8 \%,{ }^{29}$ and that the proportion of women who started HRT at more than 55 years of age in a survey conducted in 2003 was $9 \%{ }^{23}$ Consistent with those reports, the percentage of women who started HRT at more than 55 years of age in the present study was $9.1 \%$.

In the present study, the prevalence of HRT use in women who had undergone bilateral oophorectomy was high, although the prevalence of HRT use in women who had undergone hysterectomy was similar to that in women who had not 
undergone hysterectomy and oophorectomy. Further detailed study on HRT prevalence in women who have undergone bilateral oophorectomy is needed.

Because the JNHS was a long-term study, the prevalence of HRT use determined in the present study is considered to be close to the true lifetime prevalence, and that is a strength of the present study. However, this study has several limitations. First, we asked about OCs as exogenous hormones other than those used in HRT and did not ask about age of starting and duration of taking OCs in detail. Since there have been changes in social situations, such as the addition of insurance coverage for treatment of endometriosis by OCs in 2008 and the introduction of low-dose estrogen and progestin, it is difficult to determine whether the drugs taken by women during the 10-year period in this study were actually OCs. Second, the results of the present study may not be applicable to women in general, since the subjects of this study were nurses, who have easier access to medications. Third, we could not obtain information on the precise dates of stopping and resuming HRT use, but we had asked year of age when they started and stopped HRT use in the biennial follow-up surveys. We considered a duration of HRT use for less than 1 year as 0.5 years and took into account HRT users whose duration of use was less than 1 year in Kaplan-Meier calculations. Thus, this may not affect the results of this study.

In conclusion, the lifetime prevalences of OC use and HRT use were $6.0 \%$ and $13.8 \%$, respectively, in Japanese nurses in this prospective study. The results of this study will be useful in future research clarifying the association between exogenous estrogen exposure and estrogen-related diseases.

\section{ACKNOWLEDGEMENTS}

The authors appreciate the cooperation of all of the nurses who participated in the present study. They are grateful to Ms Naho Maruoka and Ms Satomi Shimizu for assistance with study coordination and data management.

Funding: This work was supported by the Japan Society for the Promotion of Science [grant number 18H04069 to KH], the Japan Agency for Medical Research and Development [grant number 19gk0210020h0002 to KH], and the Japan Society for Menopause and Women's Health [2018 grant to YI].

Conflicts of interest: None declared.

Contributors: Toshiyuki Yasui wrote the first draft of the paper. Toshiyuki Yasui, Yuki Ideno, Kazue Nagai and Kunihiko Hayashi statistically analyzed the data. Kunihiko Hayashi was the principal investigator of the Japan Nurses' Health Study (JNHS) project. Toshiyuki Yasui, Hiromitsu Shinozaki, and Yoshikazu Kitahara collected detailed information on OC and HRT use. All authors contributed to the final draft of the paper, had full access to the data, and take responsibility for the integrity of the data and the accuracy of data analysis.

\section{REFERENCES}

1. Mosher WD, Jones J. Use of contraception in the United States: 1982-2008. Vital Health Stat. 2010;23:1-44.

2. Yoshida H, Sakamoto H, Leslie A, Takahashi O, Tsuboi S, Kitamura K. Contraception in Japan: current trends. Contraception. 2016;93: 475-477.

3. Rossouw JE, Anderson GL, Prentice RL, et al; The Writing Group for the WHI Investigators. Risks and benefits of estrogen plus progestin in healthy post-menopausal women: principal results of the
Women's Health Initiative randomized controlled trial. JAMA. 2002; 288(3):321-333.

4. Anderson GL, Limacher M, Assaf AR, et al; Women's Health Initiative Steering Committee. Effects of conjugated equine estrogen in postmenopausal women with hysterectomy. The Women's Health Initiative Randomized Controlled Trial. JAMA. 2004;291:17011712.

5. Hersh AL, Stefanick ML, Stafford RS. National use of postmenopausal hormone therapy. Annual trends and response to recent evidence. JAMA. 2004;291:47-53.

6. Ameye L, Antoine C, Paesmans M, de Azambuja E, Rozenberg S. Menopausal hormone therapy use in 17 European countries during the last decade. Maturitas. 2014;79:287-291.

7. de Villiers TJ, Hall JE, Pinkerton JV, et al. Revised global consensus statement on menopausal hormone therapy. Climacteric. 2016;19: 313-315.

8. Lobo RA, Pickar JH, Stevenson JC, Mack WJ, Hodis HN. Back to the future: hormone replacement therapy as part of a prevention strategy for women at the onset of menopause. Atherosclerosis. 2016;254:282-290.

9. Antoine C, Ameye L, Paesmans M, de Azambuja E, Rozenberg S Menopausal hormone therapy use in relation to breast cancer incidence in 11 European countries. Maturitas. 2016;84:81-88.

10. Peng W, Adams J, Hickman L, Sibbritt DW. Complementary/ alternative and conventional medicine use among menopausal women: results from the Australian longitudinal study on women's health. Maturitas. 2014;79:340-342.

11. Nagata C, Matsushita Y, Shimizu H. Prevalence of hormone replacement therapy and user's characteristics: a community survey in Japan. Maturitas. 1996;25:201-207.

12. Crawford SL, Crandall CJ, Derby CA, et al. Menopausal hormone therapy trends before versus after 2002: impact of the Women's Health Initiative Study Results. Menopause. 2018;26:588-597.

13. Bhupathiraju SN, Grodstein F, Rosner BA, et al. Hormone therapy use and risk of chronic disease in the Nurses' Health Study: a comparative analysis with the Women's Health Initiative. Am J Epidemiol. 2017;186:696-708.

14. Hundrup YA, Ekholm O, Høidrup S, Davidsen M, Obel EB. Risk factors for hip fracture and a possible effect modification by hormone replacement therapy. The Danish Nurse Cohort Study. Eur J Epidemiol. 2005;20:871-877.

15. Løkkegaard E, Nielsen LH, Keiding N. Risk of stroke with various types of menopausal hormone therapies. A national cohort study. Stroke. 2017:48:2266-2269.

16. Rothman KJ, Greenland S, Lash TL. Modern epidemiology. $3^{\text {rd }}$ ed. Lippincott Williams \& Wilkins. Philadelphia. 2008:46-49.

17. Hayashi K, Mizunuma H, Fujita T, et al. Design of the Japan Nurses' Health Study: a prospective occupational cohort study of women's health in Japan. Ind Health. 2007;45:679-686.

18. Yasui T, Hayashi K, Mizunuma H, et al. Factors associated with premature ovarian failure, early menopause and earlier onset of menopause in Japanese women. Maturitas. 2012;72:249-255.

19. Lundberg V, Tolonen H, Stegmayr B, Kuulasmaa K, Asplund K; WHO MONICA Project. Use of oral contraceptives and hormone replacement therapy in the WHO MONICA project. Maturitas. 2004;48:39-49.

20. Rashed AN, Hsia Y, Wilton L, Ziller M, Kostev K, Tomlin S. Trends and patterns of hormonal contraceptive prescribing for adolescents in primary care in the UK. J Fam Plann Reprod Health Care. 2015;41:216-222.

21. Kitamura K. The pill in Japan: will approval ever come? Fam Plann Perspect. 1999;31:44-45.

22. Kinoshita T, Tanaka S, Inagaki M, Takeuchi M, Kawakami K. Prescription pattern and trend of oral contraceptives in Japan: a descriptive study based on pharmacy claims data (2006-2014). Sex Reprod Healthc. 2018;17:50-55.

23. Strothmann A, Schneider HPG. Hormone therapy: the European women's perspective. Climacteric. 2003;6:337-346.

24. Okano H, Higuchi $\mathrm{T}$, Kurabayashi $\mathrm{T}$, et al; Subcommittee for Revising the Japanese Guidelines for Hormone Replacement 
Therapy in the Women's Health Care Committee, Japan Society of Obstetrics and Gynecology. Japan Society of Obstetrics and Gynecology and Japan Society for Menopause and Women's Health 2017 guidelines for hormone replacement therapy. J Obstet Gynaecol Res. 2018;44:1355-1368.

25. Du Y, Dören M, Melchert HUW, Scheidt-Nave C, Knopf H. Differences in menopausa hormone therapy use among women in Germany between 1998 and 2003. BMC Womens Health. 2007;7:19.

26. Baber RJ, Panay N, Fenton A; IMS Writing Group. 2016 IMS recommendations on women's midlife health and menopause hormone therapy. Climacteric. 2016;19:109-150.
27. Banks E, Barnes I, Baker K, Key TJ; EPIC Working Group on Reproductive and Hormonal Factors. Use of hormone therapy for menopause in nine European countries. IARC Sci Publ. 2002;156: 301-303.

28. Buist DSM, Newton KM, Miglioretti DL, et al. Hormone therapy prescribing patterns in the United States. Obstet Gynecol. 2004; 104:1042-1050.

29. Manzoli L, Di Giovanni P, Del Duca L, et al. Use of hormone replacement therapy in Italian women aged 50-70 years. Maturitas. 2004;49:241-251 